\title{
Incorporating Innovative Pedagogies into Accounting Curriculum: Results from a Game Lab Implementation
}

\author{
Genevieve Scalan \\ Texas A\&M University - Kingsville \\ Kendra Huff \\ Texas A\&M University - Kingsville
}

\begin{abstract}
Students often seem to have difficulty retaining knowledge from one semester to another. An accounting lab employing simulations and games was developed and implemented as a means of improving student learning outcomes and knowledge retention for Principles of Financial Accounting. A comparison of grades from previous semesters with semesters during which the lab was implemented, as well as survey results, found that, in addition to improving financial accounting skills, student satisfaction with accounting coursework improves. Just as important, the D-F-W rate has continued to drop since the implementation of the lab.
\end{abstract}

Keywords: principles of accounting, interactive lab, accounting education

\section{INTRODUCTION}

Texas A\&M University - Kingsville (TAMUK) is located in South Texas and serves a variety of traditional and non-traditional students, many of them first generation college students. Faculty recognized that students in the first principles course seemed to have trouble retaining the information through to the end of the semester and on to other, upper level classes. As a means of improving student learning outcomes, an accounting lab, employing simulations and games, was developed and implemented for Principles of Financial Accounting. A comparison of grades from previous semesters with semesters during which the lab was implemented, along with survey results, found that in addition to improving financial accounting skills, student satisfaction with accounting coursework improved. We further found additional unanticipated positive outcomes for students in the areas of team skills and leadership.

The paper herein will provide a background of TAMUK, prior assessments and reasons for initiating the lab; research and steps taken to prepare for the lab; a summary of topics, simulations, and games; student learner outcomes; methodology and results; and, lessons learned and plans for the future. 


\section{BACKGROUND}

\section{Demographics}

TAMUK was originally established in the small town of Kingsville, TX, as South Texas Teachers College in 1925. It has evolved through the years from the small teaching college to Texas College of Arts \& Industries (1927) to Texas A\&I University (1967) and finally, Texas A\&M University-Kingsville (1993) after it became part of the A\&M University System in 1989. Kingsville is located about 40 miles south of Corpus Christi, TX, and about 90 miles north of the Rio Grande Valley. Most recent statistics show an enrollment of 8,566 students (6,990 undergraduates). Reflective of the University's location, 73 percent of the student body is comprised of those who are of Hispanic ethnicity (TAMUK, 2018). The College of Business has an enrollment of 549 for the Fall 2018 semester, up 43 percent from 2013. The College is accredited by the AACSB.

\section{Principles of Accounting Course Evaluation}

At the beginning of every semester, college faculty participates in workshops to evaluate prior semesters' learning assessment outcomes and to brainstorm improvements to curricula and pedagogy. Prior to the Spring 2016 semester, one discussion focused on the fact that while demand for accounting professionals is growing, the enrollment in the accounting program at TAMUK has not participated in this growth. In addition, anecdotal evidence suggests that the percentage and success of accounting students from the program that choose to take the CPA exam may be declining. The College's CPA pass rate was at an average of 23 percent and, on average, only one TAMUK graduate per year became a CPA in Texas over the ten years between 2005 and 2015 (TSBPA, 2016). Furthermore, an examination of course grades show that as many as half the students in principles of accounting either failed or dropped the class leading to the conclusion that the learning outcomes of the principles of accounting classes are not at the desired levels and the level of preparedness of students leaving the principles sequence is not where it should be, leading to the necessity of some sort of intervention.

\section{LITERATURE REVIEW}

\section{Minority and First Generation}

A 2012 study by the Department of Education found that most first-generation students were nonwhite students, including 61 percent Latino (Postsecondary National Policy Institute, 2018). Other studies show that not only do first-generation students tend to be minorities, they also come from low-income families with single parents and are paying for college on their own. They are less likely to continue their college education, with about 26 percent, as compared to seven percent of students who aren't first generation, of them ending their college career after just one year. And, while 55 percent of others obtain their degrees, only about 11 percent of first-generation students obtain theirs (National Center for Educational Statistics, 2016).

Numerous problems get in the way of the first-generation student's college success. Two main issues that are pertinent to this study are a lack of academic preparation and lack of participation in college activities. First-generation students many times enter college unprepared and are required to attend remedial courses. Unfortunately, only about one-third of these students graduate. Since they often have to work, many first-generation students don't join groups of any type, social or academic. A way to keep students engaged and on campus for longer periods of time would be beneficial to their success (America's Promise Alliance, 2012). Mandatory lab attendance provides a method for better preparing students academically and for increasing contact time, both of which should help increase their chances for academic success.

\section{The Accounting Profession}

In 2015, the AICPA and the AAA published a report concerning accounting curricula and the success of accounting students. According to the report, the ideal knowledge growth for students would be to start 
with "black and white judgements" moving to "accounting judgements that analyze the ambiguity (shades of gray) of the economic activities to report and evaluate useful information for resolving business issues and making good decisions" (p. 8). Towards that end, students should have a variety of learning experiences, among them, those that are "pervasive and routine" (p. 7). Throughout their college career, students should also participate in "public performances that remove the cloak of invisibility; be held accountable for their work to clients, student peers, faculty, and others; be active and interactive; and, experience adaptive anxiety" (p. 7).

The study also addressed technology. Focus groups consisting of practitioners and academia were asked, "What technologies should accounting students know to be successful in the accounting workplace?" (p. 10). All agreed that accounting students should be proficient with spreadsheets. As a matter of fact, spreadsheet competency was ranked first on a list of twenty-five technologies that students should know. Incorporating the use of technology, spreadsheet technology specifically has become very important at all levels of the curriculum (Pathways Commission, 2015).

\section{Benefits of an Interactive Lab}

As a means of addressing the above topics and improving learning outcomes for all students in the accounting principles course, the addition of a lab of the interactive type was investigated. Tanner \& Lindquist (1998) found that the use of an accounting simulation game based on Monopoly ${ }^{\mathrm{TM}}$ resulted in improved student attitudes toward accounting, the learning of accounting and enhanced achievement. In another study, the principles course, which had been structured as a lecture course supported by homework review sessions conducted by teaching assistants, was restructured to include two-hour laboratory sections that were carefully integrated with the course and led by specially trained teaching assistants. The restructure resulted in lectures that focused primarily on knowledge development and labs that focused on skill building activities. As a result, students' understanding of specific business practices, motivation to study business and accounting, study habits and understanding of economic realities were improved (Shaftel \& Shaftel, 2005). In an experiment conducted by Opdecam and Everaert (2012), students report experiencing a more positive course experience with team based learning compared to students in a lecture only class. The study also demonstrated improved grades for students on teams.

In addition to a review of the literature, three faculty members also traveled to Russellville, Arkansas, and observed the Arkansas Tech accounting lab. While there, the TAMUK faculty was presented with information on the lab and its outcomes. Arkansas Tech reported that the percentage of students who either dropped or received an " $\mathrm{F}$ " improved from more than 60 percent to less than 30 percent after the first semester the accounting lab was instituted and that those improved results have been sustained in subsequent semesters. Based on the literature review and the visit to Arkansas Tech, TAMUK faculty decided to create a lab appropriate for TAMUK students beginning Fall 2016.

\section{Lab Implementation}

In the development of the lab, the first step was the establishment of lab specific learning objectives to help ensure a positive experience and outcome for students. The learning objectives were relatively basic for any accounting principles course:

- Students will recognize and record financial accounting transactions.

- Students will properly record adjusting and closing entries.

- Students will complete the accounting cycle and prepare basic financial statements.

It was felt that lab attendance was imperative if the lab was to be successful. Therefore, the lab was created as a separate zero credit hour course for which students registered at the time they registered for the principles class thus reinforcing the idea that the lab is an integral part of the Principles class and not optional. Prior to selecting times for labs, the lab developers met with constituents and found labs later in the day were required to work around student schedules. To accommodate both students who work and student athletes, one hour labs were scheduled between the hours of 4:00pm and 6:00pm, which students were required to attend twice a week. The idea behind the required attendance twice a week is 
multifaceted: more contact hours for first generation students; loosely formed study groups as the lab is more informal than actual classroom setting; and, added hours and hands on learning should help with knowledge retention.

As part of the lab, students play games, such as Monopoly, or work through simulations in groups or teams. A room allowing for such interaction would greatly improve the success of the lab. While lab was initially conducted in the student lounge, an interactive lab was completed in Fall 2016. The interactive lab is furnished with enough square, moveable tables to seat 50 students. Furthermore, tables can be positioned so that each group has access to a computer and large screen monitor which can be used for group work. The instructor can also display instructions on each monitor.

Given that it is believed that lab enrollment is constrained by the instructor's ability to monitor a limited number of students at each table, it was decided to limit lab enrollment to fifty students. For the College, that translated to four separate labs to accommodate the approximate two-hundred accounting principles students each semester. Two accounting faculty each teach between one to three course sections of Principles of Financial Accounting and supervise the labs to ensure that in-class content is being reinforced in the lab. Graduate assistants (GA) are employed to interact with and assist the students as the simulations are played. The GAs also perform grading functions for the class sections as well as provide on-site assistance for the labs. While not required to be an accounting major, it is preferred that the GAs have completed an accounting course at either the undergraduate or graduate level.

Finally, specific lessons plans were prepared for each lab session. These lesson plans included detailed instructions on the activities and the roles of instructors, GAs, and students. The lab designer determined the activities for each lab session and created the lesson plan and supporting documents used for the session. For example, for the lab intended to teach bank statement reconciliation, simulated checks, deposit slips, and a bank statement were created for use in the lab. For retail transactions, students are asked to record transactions for a candy store while exchanging actual candy. Depreciation entries are practiced with toy 'equipment' that they purchased. Jeopardy and Family Feud provide additional reinforcement and are utilized as class reviews. Table 1 provides a summary of topics and the lab activities used to reinforce them. 


\section{TABLE 1 \\ SUMMARY OF TOPICS AND LAB ACTIVITIES}

\begin{tabular}{|l|l|}
\hline Lab\# & In Class Activities \\
\hline 1 & Monopoly - Learn to play and look over the Chart of Accounts \& "journal" \\
\hline 2 & Jeopardy - Introduction to accounting based on the first 11 pages of the text. \\
\hline $3-4$ & Monopoly - Journalize Transactions \& Posting \\
\hline 5 & Review for Exam 1 \\
\hline 6 & Excel - Uses for preparing adjusting entries and financial statement worksheet. \\
\hline $7-8$ & Monopoly - Adjusting Entries; preparing financial statements \\
\hline 9 & Review for Exam 2 \\
\hline 10 & Family Feud. Accounting Cycle topics \\
\hline 11 & Monopoly - Using Checks instead of currency - Reconcile Bank statement \\
\hline 12 & The Candy Store - Purchase \& Sales Transactions \\
\hline 13 & Review for Exam 3 \\
\hline 14 & Jeopardy - Information to date \\
\hline 15 & The Candy Store. - LIFO/FIFO using Smarties and DumDums in a wholesale candy store \\
\hline 16 & Rihanna World Tour Merchandise - Direct vs Allowance Write Offs for a T shirt/poster store \\
\hline 17 & Review for Exam 4 \\
\hline $18-19$ & Javelina Mining and Construction - Toy Construction Equipment Depreciation \& Book Value \\
\hline 20 & Review for Exam 5 \\
\hline 21 & Family Feud. - Categories could be any accounting topic so far. \\
\hline 22 & Monopoly - Using Notes Payable instead of Cash - LT Debt Transactions \\
\hline 23 & Monopoly - Additional Transactions using daily transactions and stock. \\
\hline 24 & Review for Exam 6 \\
\hline 25 & Jeopardy! Topics to date \\
\hline 26 & Monopoly - Reinforce all transactions \\
\hline 27 & Monopoly - Preparing Cash Flow Statements \\
\hline 28 & Javelinas vs Islanders - Using FSA to compare two organizations \\
\hline 28 & Review for Comprehensive Final exam \\
\hline
\end{tabular}

\section{METHODOLOGY AND RESULTS}

\section{Preliminary Observations}

The lab was implemented for Fall 2016 and has been a required element of the Principles of Accounting course since that time. Preferable, a control class section not requiring a lab would be offered as a comparison to class sections where the lab is required. However, this was not possible. As an alternative, one instructor taught Principles of Financial Accounting in the two semesters before adding the lab, as well as after the lab was added, which allowed for an examination of pre and post lab treatment with the instructor variable remaining stable. For this instructor, prior classes resulted in an average of 36 percent of students having an unfavorable outcome, defined as a student earning a final letter grade of D or F or dropping the class. In the post-lab treatment group for the same instructor, unfavorable student outcomes dropped to 18 percent and have continued to fall, averaging 10.2 percent through Spring 2019.

The lab also resulted in some educational achievements perceived by instructors as being beneficial to all students including first-generation students. The structure of the lab necessitates students work together in team scenarios. We know from Tanner and Lindquist (1998) that students working together using Monopoly were found to demonstrate more positive attitudes toward learning accounting and selfperceptions of their own achievement improved. As students interacted in the TAMUK lab, instructors noticed students began to interact with one another more often and in some cases, team leaders arose organically in the context of the more competitive games. Additional preliminary anecdotal evidence also indicated that students' interest level in accounting education may increase for students in the lab. 


\section{Methodology}

To determine the impact of the lab on student success in the principle course, for all four sections of Principles of Accounting, regression analysis was performed to determine whether student performance on exams was improved by lab attendance, with the hypothesis being that said attendance would have a positive impact on exam performance. Exam performance was chosen rather than overall grade since lab attendance is part of the overall grade and collinearity would have been a problem.

A survey was also administered to students after the semester was concluded to gather their thoughts on the lab. The survey was administered via Survey Monkey after the conclusion of the semester so that students would not feel as though their response would have an impact on their grade in the course. The survey consisted of six descriptive elements and five attitudinal elements.

\section{Results}

As shown in Figure 1, based on the regression results and as expected, lab attendance had a positive and significant effect on exam performance. The analysis was performed on a sample of 517 observations from all class sections from the Fall 2016 through Spring 2019 semesters. Although the R-squared, at 23 percent, appears lower than expected, it was significant. Many other factors affect exam grades such as study time spent outside of lab and class, completion of homework, etc.

Not only is the lab expected to improve performance in the principles courses, it is also hoped that the hands on approach of the lab will improve knowledge retention. The effect of the lab was analyzed on the overall grade in the second principles course during the Spring 2018 and Spring 2019 semesters by including a dummy variable for the lab. The results are presented in Figure 2. Unfortunately, the lab does not seem to have any impact on performance in the second principles course. Furthermore, an analysis of exam averages in an upper level financial statement analysis course also do not appear to be impacted by whether students had been enrolled in the interactive lab or not. Thus, the biggest impact of the lab is a positive correlation with the grade in the principles course as well as the decrease in the D-F-W rate for that course.

FIGURE 1

PRINCIPLES OF FINANCIAL ACCOUNTING - FALL 2016 THROUGH SPRING 2019

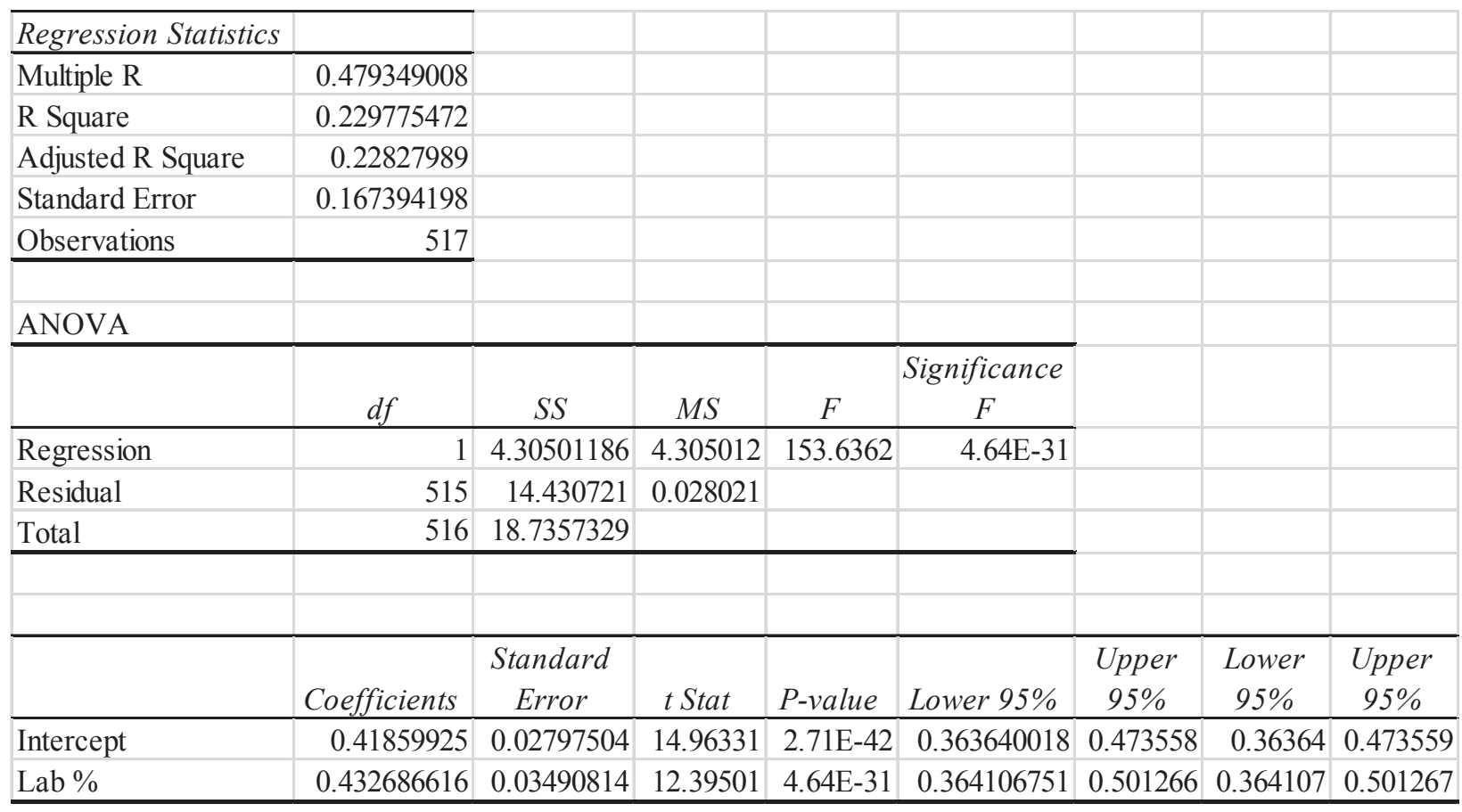


FIGURE 2

PRINCIPLES OF MANAGERIAL ACCOUNTING - SPRING 2017 THROUGH SPRING 2019

\begin{tabular}{|c|c|c|c|c|c|c|c|c|}
\hline \multicolumn{9}{|l|}{ Regression Statistics } \\
\hline Multiple R & 0.04715066 & & & & & & & \\
\hline R Square & 0.00222318 & & & & & & & \\
\hline Adjusted R Square & -0.0060229 & & & & & & & \\
\hline Standard Error & 22.6831053 & & & & & & & \\
\hline Observations & 123 & & & & & & & \\
\hline & & & & & & & & \\
\hline \multicolumn{9}{|l|}{ ANOVA } \\
\hline & $d f$ & $S S$ & $M S$ & $F$ & $\begin{array}{c}\text { Significance } \\
F \\
\end{array}$ & & & \\
\hline Regression & 1 & 1387179 & 138.7179 & 0.269605 & $\overline{6.05 \mathrm{E}-01}$ & & & \\
\hline Residual & 121 & 62257.32 & 514.5233 & & & & & \\
\hline \multirow[t]{3}{*}{ Total } & 122 & 62396.03 & & & & & & \\
\hline & & & & & & & & \\
\hline & Coefficients & $\begin{array}{c}\text { Standard } \\
\text { Error }\end{array}$ & $t$ Stat & P-value & Lower 95\% & $\begin{array}{c}\text { Upper } \\
95 \% \\
\end{array}$ & $\begin{array}{c}\text { Lower } \\
95 \% \\
\end{array}$ & $\begin{array}{c}\text { Upper } \\
95 \% \\
\end{array}$ \\
\hline Intercept & 70.8006614 & 3.780518 & 18.72777 & $1.49 \mathrm{E}-35$ & 63.3161297 & 78.28519 & 63.31613 & 78.28519 \\
\hline Lab \% & 2.33403808 & 4.49515 & 0.519235 & $6.05 \mathrm{E}-01$ & -6.565297 & 11.23337 & -6.5653 & 11.2337 \\
\hline
\end{tabular}

Survey results (Figure 3) show that students seemed to appreciate the lab environment. Seventy-two percent of students agreed the games in the lab helped them learn accounting, while 76 percent agreed that it made lab more fun and interesting than expected. Sixty percent noted that they would take another course with a similar lab. As for teamwork, 64 percent of students liked the team aspect of the lab. Overall, students seemed very satisfied with the lab experience. 
FIGURE 3

SURVEY RESULTS

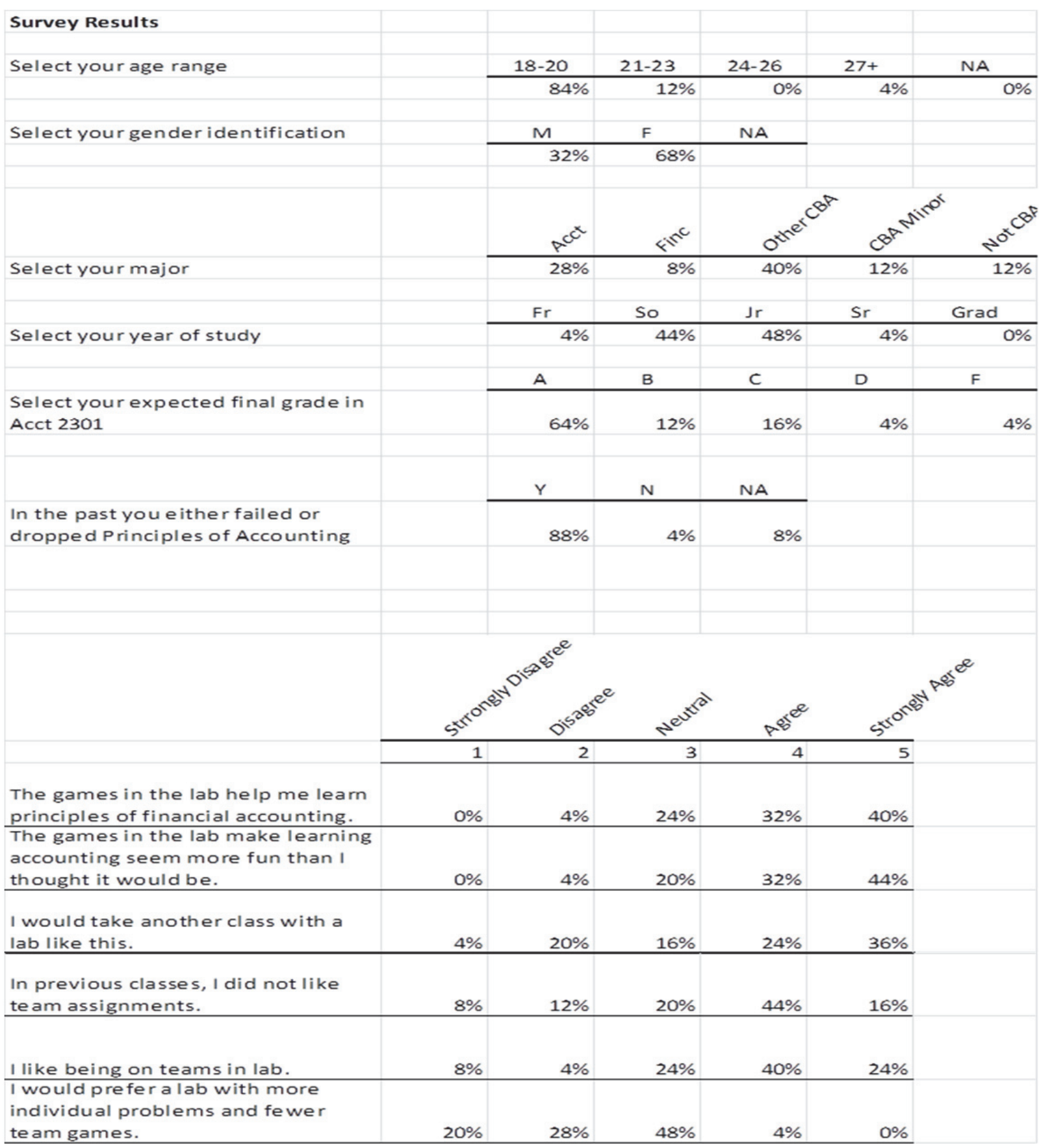

148 Journal of Higher Education Theory and Practice Vol. 20(1) 2020 


\section{CONCLUSION}

The establishment of the interactive learning lab was not without its difficulties. While the lab was implemented in Fall 2016, the dedicated interactive lab room was not yet available and lab was conducted in the student lounge. While it worked, the lounge was not really furnished to accommodate 50 students working in teams and playing games. The dedicated room was complete in the Fall 2017 and has since worked out very well. Students really appreciate how the room is structured for team work and interactive teaching.

GAs have proven to be very useful in the lab environment. A single instructor trying to help numerous teams does not always work out. GAs generally have had some sort of accounting course and, if necessary, instructors go over the topic of the day with them prior to lab. The GAs also assist with the increased paperwork that comes with the lab. They record attendance, prepare any necessary lab papers, grade homework, and post grades online. The amount of time required for lab and the increased work that goes along with it would have been quite cumbersome if not for the GAs.

The lab topics to be covered in each lab session are intended to reinforce what was covered in class, requiring some syllabus adjustment from semester to semester and for MWF versus TR classes. Summer courses also require adjustment as the class meets M-F while lab meets MW. A little bit of flexibility from all parties goes a long way.

Overall, the lab appears to be successful. While students originally gripe about having to attend a lab twice a week for an hour, they ultimately attend regularly and have a good time while learning the principles of accounting. Many of them also enjoy the higher exam grades that the extra study time in lab leads to. One of the goals of the lab, however, was to increase knowledge retention as the students complete their degree. This goal does not seem to have been realized. The addition of a lab to the second principles course is currently being scrutinized and will perhaps help the college reach that goal. 


\section{REFERENCES}

America's Promise Alliance. (2012). Improving access and success for first-generation college students. Retrieved from http://www.americaspromise.org/news/ improving-access-and-success-firstgeneration-college-students.

National Center for Educational Statistics. (2016). College Navigator. Retrieved from $\mathrm{http}: / /$ nces.ed.gov/collegenavigator/?q=texas $+\mathrm{a}+\% 26+\mathrm{M}+$ University + Kingsville $\& \mathrm{~s}=$ all\&id $=2287$ 05 .

Opdecam, E., \& Everaert, P. (2012). Improving student satisfaction in a first-year undergraduate accounting course by team learning. Issues in Accounting Education, 27(1), 53-82.

Postsecondary National Policy Institute. (2018). Factsheets: First Generation Students. Retrieved from http://pnpi.org/first-generation-students/.

Shaftel, J., \& Shaftel T. (2005). The Influence of Effective Teaching in Accounting on Student Attitudes, Behavior, and Performance. Issues in Accounting Education, 20(3), 231-246.

Tanner, M. M., \& Lindquist, T. M. (1998). Teaching Resource Using Monopoly ${ }^{\mathrm{TM}}$ and Teams-Games Tournaments in Accounting Education: A Cooperative Learning Teaching Resource. Accounting Education, 7(2), 139-162.

Texas A\&M University - Kingsville. (2018). Student Enrollment by Demographics. Retrieved from http://www.tamuk.edu/oir/Tableau_Student_Dashboard/TAMUK_Dashboards.html.

Texas State Board of Public Accountancy. (2016). University Statistics Candidate Success Rate-CBT Uniform CPA Examination. Retrieved from http://www.tsbpa.state.tx.us/ statistics/universitystatistics.html.

The Pathways Commission. (2015). In Pursuit of Accounting's Curricula for the Future. American Accounting Association and the American Institute of Public Accountants. Retrieved from ommons.aaahq.org/files/3968045e18/Pathways_Report_4_For_Print.pdf. 